
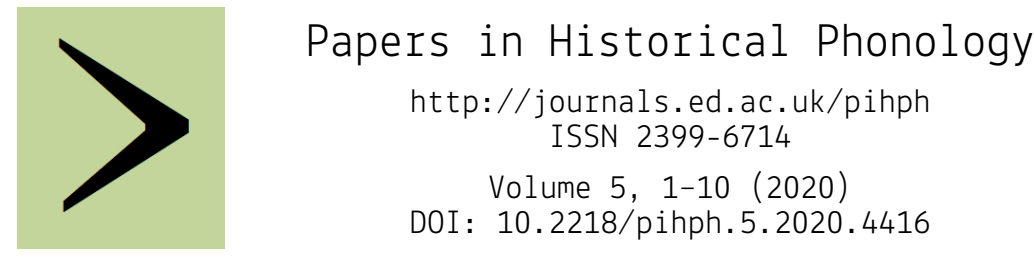

DOI : $10.2218 /$ pihph.5.2020.4416

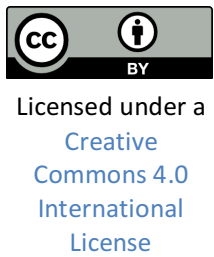

\title{
The lowering of high vowels before [r] in Latin
}

\author{
ANDRÁS CSER \\ Pázmány Péter Catholic University
}

\begin{abstract}
This paper discusses a putative sound change in the early history of Latin and synchronic alternations apparently related to it. The lowering of short high vowels before the rhotic is problematic on several counts; so much so that serious doubt has been cast on its reality. On the other hand, due to widespread alternations in the morphophonology of Classical Latin it is reasonable to assume that such a lowering operated as a synchronic rule at that stage. A minor asymmetry in the relevant alternations of verbal affixes in infectum-based vs. perfectum-based formations presents an interesting problem to which I suggest two tentative explanations.
\end{abstract}

\section{Introduction}

Practically all historical discussions of the Latin sound system or morphological system, as well as several studies of a narrower scope, mention a sound change in which the short high vowels were lowered to mid vowels before the rhotic, thus Early Latin [ir], [ur] > [er], [or]. ${ }^{1}$ This change is interesting for two reasons. One is that there are so many problems surrounding it (presented below in section 2) that even its reality has been seriously doubted by some. The other is that pervasive vocalic alternations in the Latin morphological system (presented below in section 3.1 and, more fully, in Cser 2015, 2020) appear to derive from it. It is therefore the goal of this paper to critically review the various descriptions of this putative change in order to understand how exactly it unfolded and how it relates to the attested morphophonological alternations; but, more importantly, it is also my goal here to explain why

${ }^{1}$ See Sommer $(1902,78-84)$, Sommer \& Pfister $(1977,58)$, Buck $(1933,79)$, Meillet $(1933,140)$, Leumann $(1977,50-51)$, Parker $(1988)$, Meiser $(1998,68)$, Baldi $(2002$, 246), Weiss $(2009,142)$, Sen $(2015,82)$. On the phonetics of such processes see Recasens (1990, 1991), Recasens \& Pallarès (1999), Hall \& Hamann (2010). 
the alternations in question are not uniform in terms of the relation between environments and alternants. As will be argued, it is possible to give such an explanation in a rule-based framework (as in section 3.2) as well as in a pattern-based, quantitative approach (as in section 3.3), though both will be presented here only semi-formally.

\section{The lowering: problems with the interpretation of the change}

The first question concerns the precise segmental environment of the lowering; to wit, whether it was triggered by all [r]'s or only those resulting from rhotacism, another Early Latin sound change whereby $* \mathrm{~V}[\mathrm{~s}] \mathrm{V}>\mathrm{V}[\mathrm{r}] \mathrm{V}$. The majority opinion seems to be the latter; Parker (1988), Meiser (1998) and Weiss (2009) are exceptions in not restricting the environment of lowering to before $[\mathrm{r}]<*[\mathrm{~s}]$. The apparent advantage of the more restrictive view is that it explains the difference between e.g. sero < *siso 'sow' and vir < *wiros 'man'. On the other hand, there is no additional evidence that, once rhotacism had been completed, its outcome was phonetically different from the original rhotic.

The second question concerns the prosodic environment of the change. Did it affect the high vowels in all syllables or only non-initial syllables? The majority opinion is the former, although it is well nigh impossible to find examples other than sero for initial-syllable lowering of [i] (for [u] see below); only Pfister (Sommer \& Pfister 1977), Meiser (1998) and Sen (2015) restrict the change to non-initial syllables. Importantly, the latter three authors discuss the lowering not as a selfcontained change but as part of the general neutralisation of short vowels in non-initial syllables known as 'Old Latin weakening'. In the course of this change all short vowels in non-initial open syllables neutralised to [i] except before [r] where they neutralised to [e]. ${ }^{2}$

Related to this is the third question: did the change affect the high vowels in all syllables or only in open syllables? The majority opinion appears to be the latter, which is consistent with the rhotacism-related majority view (viz. the vowel before a [r] from rhotacism is necessarily in an open syllable, see above), although Weiss (2009) does not make the connection explicit.

The fourth question is this: was the palatal and the velar development parallel, that is, do we really have [ir], [ur] $>$ [er], [or] in an identical environment, whatever it was? The majority opinion seems

\footnotetext{
2 For examples and details of the weakening, which are rather complex, see e.g. Leumann (1977, 79-91), Sihler (1995, 59-64), Meiser (1998, 67-73), Baldi (2002, 253-256) or Sen $(2015,80-88)$.
} 
to be no, with Buck (1933), Parker (1988) and Baldi (2002) as exceptions, and the authors tend to express some uncertainty or reservation about the [ur] $>$ [or] side of the change. A careful examination of the literature reveals that there is practically only one generally accepted example, fore $(t)<{ }^{*} b^{h} u-s \bar{e}-(t)$ 'would be'. In view of this, authors offer a variety of explanations for why the change did not happen anywhere else. According to Meillet (1933) and Leumann (1977) it was blocked by a following [u] or [w] (hence furvus 'dark', nurus 'daughter-in-law'); according to Weiss (2009) it was blocked in closed syllables (hence furvus 'dark'); according to Sommer (1902) it was blocked in stressed syllables, hence the lowering in fore( $t)$, which was enclitic and thus unstressed.

The fifth question is the simplest of all: why are there so many apparent counterexamples? Nearly all of the authors cited feel compelled to admit that several forms contradict the rule. The set of the actual counterexamples in each case depends, of course, on the precise formulation of the sound change, but words such as vir 'man', dirimo < ${ }^{*}$ dis-emo 'take apart', pirum < ${ }^{*} h_{2}$ pisom 'pear' are usually invoked. The answer to the question is as simple as the question itself: there are no counterexamples as long as one identifies the conditions correctly as, in fact, Pfister (Sommer \& Pfister 1977) and Meiser (1998) do. Their discussion makes it clear that there was no separate [ir] > [er] change; apparent examples simply conform to the general pattern produced by the Old Latin weakening (to recapitulate: all short vowels in non-initial open syllables neutralised to [i] except before [r] where they neutralised to [e]); furthermore, the origin of the [r] itself is immaterial. ${ }^{3}$

If one accepts this, as indeed I do, the question of sero < *siso 'sow' emerges. Is this word - the only creditable instance of lowering in an initial syllable - not a counterexample to Pfister's and Meiser's claim? It would be, on the generally held assumption that it represents present stem $\mathrm{Ci}$-reduplication, i.e. ${ }^{*} s i-s-o$. But as Rix $(2001,517)$ indicates, this form is more likely to represent Ce-reduplication, another reconstructible process for the formation of present stems in ProtoIndo-European; and so even sero ceases to be a problem. ${ }^{4}$

\footnotetext{
${ }^{3}$ In addition, there are certainly no arguments for any kind of [ur] > [or] change.

${ }^{4}$ Weiss $(2009,406)$ also mentions Ce-reduplicated presents but not in the context of sero. Pfister (Sommer \& Pfister 1977, 58) attempts to reconcile a Ci-reduplicated sero with his view that there was no lowering in initial syllables by a purported analogical transfer from weakened prefixed forms (sero instead of original *siro on the basis of regularly weakened insero 'to sow, ingraft', consero 'to plant' etc.). The problem with this explanation is that such analogical transfer of a stem vowel from prefixed to unprefixed forms is otherwise unheard of.
} 
One of the consequences of the Old Latin weakening is a pattern whereby non-initial [ir]V is indeed absent even from Classical Latin; the only exceptions are transparent compounds of vir 'man' and viridis 'green' (e.g. triumviri 'triumvirs', subviridis 'greenish'). Given this, as well as a large number of alternations going back to a variety of sound changes not discussed here (e.g. cinis ciner-is 'ash' NomSING $\sim$ GENSING), it is reasonable to assume a synchronic phonological rule of the form [ir] $\rightarrow$ [er] (in non-initial syllables) in Classical Latin, though it clearly does not result from the phonologisation of a sound change of the same form - a sound change that never happened.

\section{The morphophonological alternations}

\subsection{The general pattern}

As is explained in much greater detail elsewhere (Cser 2015, 2020), the highly varied allomorphic patterns one finds in Latin verbal as well as nominal inflection can be reduced to a series of binary alternations conditioned by the sonority of the stem-final segment. In verbal inflection nearly all cases of allomorphy fall into one of two types. Both types show a vowel-initial affix variant after stems ending in a consonant or $[\mathrm{u}]$, and a consonant-initial affix variant after stems ending in a non-high vowel. The only difference between the two types is which of the two variants they show after stems ending in [i] (see Figure 1).

Type 1

Type 2

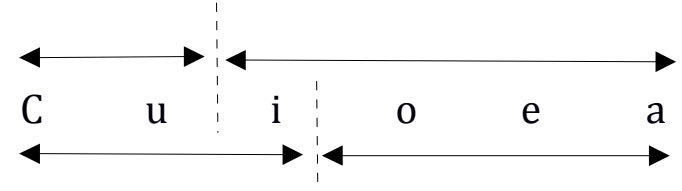

Figure 1: The distribution of affix allomorphs in verbal inflection

I exemplify the difference between the two types here from both the set of the infectum-based and perfectum-based forms (infectum and perfectum being the two stems on which all Latin finite forms and some non-finite forms are based):

(1a) Infectum Type 1: -iC(-) -C(-) and -erV(-) -rV(-)

ag-it 'do' $\sim$ veni- $t$ 'come' $\sim$ ama- $t$ 'love' PrES3SING

ag-ere 'do' veni-re 'come' ama-re 'love' INF 
(1b) Infectum Type 2: -VC(-) -C(-) ag-et 'do' veni-et 'come' ama-bit 'love' FUT3Sing

(1c) Perfectum Type 1: -isC- -sCeg-isse 'do' abi-sse 'leave' ama-sse 'love' PERFINF

(1d) Perfectum Type 2: -erV(-) -rV(-) eg-erat 'do' abi-erat 'leave' ama-rat 'love' PPF3SING

One fact to note is that, for most affixes, the vowel alternating with zero is [i] or [e], with [e] found before [r], and [i] found elsewhere. Diachronically, either affixal vowel can derive from the other:

(2) ag-it $<* a g$-et(i) 'do' Pres3SING ag-ere $<$ *ag-esi 'do' INF

eg-isse $<*$ eg-issi 'do' PERFInF

eg-erat $<$ *eg-isat 'do' PPF3Sing

Another fact to note is that the affixes of an -er-shape do not belong to the same type in the set of infectum-based vs. perfectum-based forms: see how in (1a) venire patterns with amare as opposed to agere (Type 1), and how in (1d) abierat patterns with egerat as opposed to amarat (Type 2). It is to this curious phenomenon that we now turn.

\subsection{Explaining the discrepancy: a more formal approach}

Is there a principled way to explain why affixes of such similar phonological form should display different behaviour with respect to identical phonological environments (namely, $i$-final infectum vs. perfectum verb stems)? I believe that there is, and will now attempt to outline two possibilities for the synchronic grammar of Classical Latin.

In a level-ordered model it is a possibility that affixes attach to the two verb stems on two different levels: infectum stems are affixed on Level 1, whereas perfectum stems are affixed on Level 2. Thus, for instance, a phonological rule operating on Level 1 could introduce a phonological difference between forms based on the two stems. There are two arguments that perhaps could be adduced for assigning the two classes of forms to different levels, though admittedly neither argument is compelling. One is a syntactic argument: only perfectum-based forms are systematically replaced by periphrastic formations in Latin morphology (to wit, the entire passive perfective system is periphrastic), 
which shows that the perfectum-based system is in some sense closer to the syntactic component of the grammar. The other argument is phonological: only perfectum-based formations ever stretch the boundaries of the phonotactics of the language (even if only marginally) by creating rare and highly complex consonant clusters (e.g. [jkst] in iunxti 'join' PERF2SING).

If we accept the relegation of the two morphological subsystems to two different levels, we need four ancillary hypotheses to move forward with the analysis. As we shall see, none of the four are arbitrary; they are, in fact, quite clearly motivated independently of the issue at hand.

The first ancillary hypothesis is that the default variant of all affixes is the vowel-initial one. This is supported by the general observation that inflectional affixes in Latin, whether nominal or verbal, almost never result in consonant clusters, even if these would be completely well-formed (see ag-ere 'do', cumb-ere 'lie' above in spite of pigrum 'lazy' and umbra 'shade' or hiem-ibus 'winter' DATABLPLUR in spite of nimbus 'storm' etc.). ${ }^{5}$

The second ancillary hypothesis is that the default vowel in affixes is [i], with a few affixes specified for another vowel (e.g. 3Plur -unt). Such a hypothesis is again supported by the general observation that [i] is extremely frequent in affixes. This is due in part, but not exclusively, to the Old Latin weakening, which greatly increased the number of [i]'s in non-initial syllables.

The third ancillary hypothesis is that there is a phonological rule of the form [ir] $\rightarrow$ [er] (in non-initial syllables) in the synchronic grammar of Latin. This is motivated by the large number of alternations that can be analysed as resulting from such a rule. The nominal cinis $\sim$ cineris type was mentioned in section 2 above; but we have also seen that [i] and $[\mathrm{e}]$ are in nearly complementary distribution in verbal inflectional affixes, with the main conditioning factor being the presence vs. absence of [r]. Crucially - from our point of view - this rule operates on level 1.

The fourth ancillary hypothesis is that the choice of allomorphs is governed by two simple regularities (constraints), namely identical vowels should not be adjacent $\left({ }^{*} V_{i} V_{i}\right)$ or, if two non-identical vowels are adjacent, the first should be high $\left({ }^{*} \mathrm{~V}_{[- \text {-high }]} \mathrm{V}\right)$; of the two constraints the former has precedence. This again is not arbitrary; in fact, this

\footnotetext{
5 Interestingly, the few consonant clusters that are created by inflections nearly always involve an unsyllabifiable (extrasyllabic) $s$, see iunxti above or trab-s 'beam' NOMSING.
} 
hypothesis simply encapsulates essential aspects of the general hiatus rule of Classical Latin.

Armed with these hypotheses, we arrive at the derivation seen in Figure 2 in a level-ordered model (intended here as a generic illustration rather than as an instantiation of any particular model).

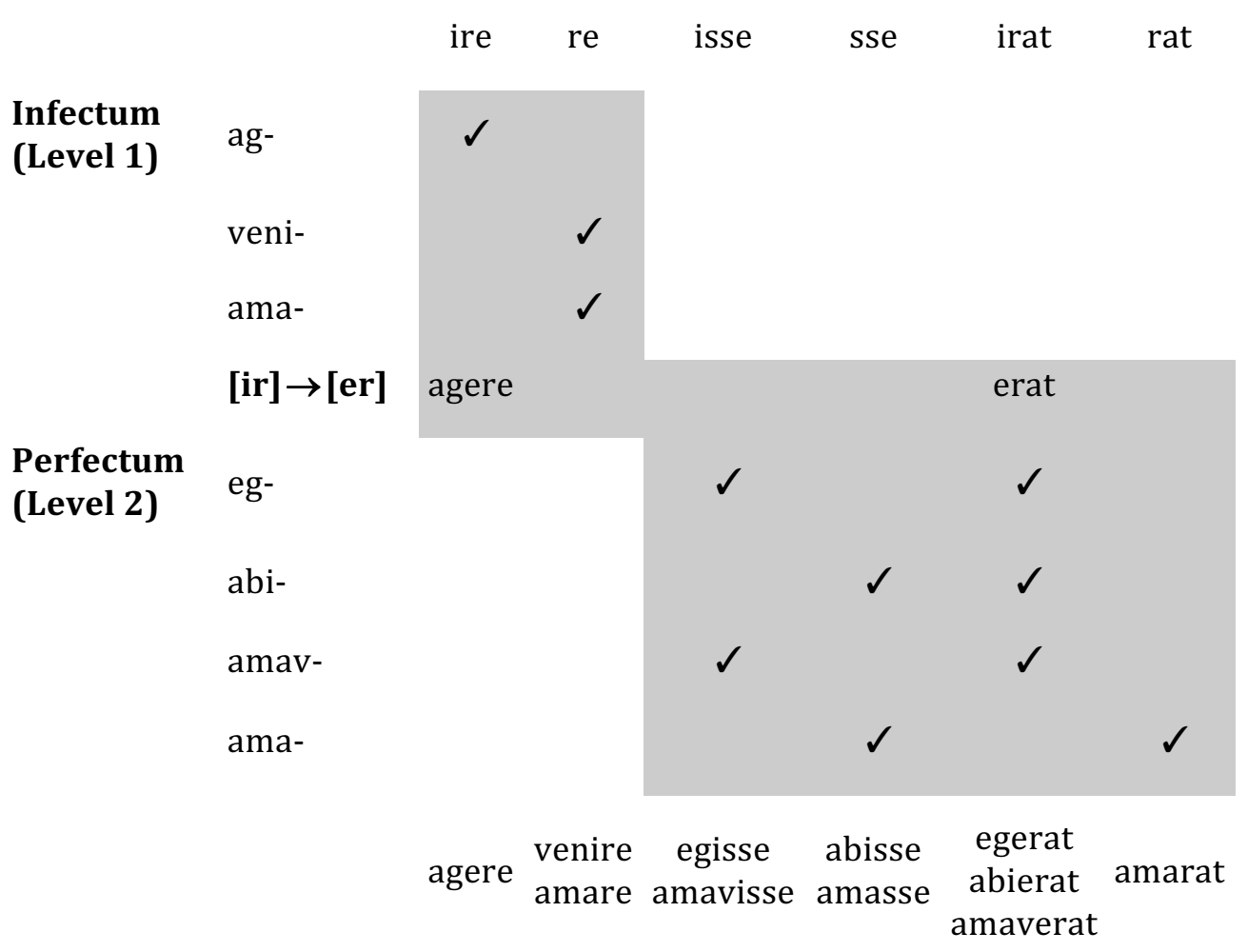

Figure 2: The derivation of the verb forms

Note that in the perfectum an optional rule deletes the $-v$-suffix, thus creating two stem variants for many verbs (amav- $\sim a m a-$, the latter incidentally identical to the infectum stem). Hence the perfect infinitive variants amasse $\sim$ amavisse with different affix allomorphs selected by the stem variants, or similarly the pluperfect 3SING forms amaverat $\sim$ amarat. This optional $v$-deletion is, in fact, the only source of non-high-vowel-final perfectum stems in Latin.

The crucial difference is illustrated by the forms venire vs. abierat: in the former the consonant-initial affix variant is selected to avoid the adjacency of identical vowels; the latter morpheme sequence, however, comes into being only after the lowering rule, hence the sequence [ie] is allowed across the morpheme boundary. 


\subsection{Explaining the discrepancy: a less formal approach}

It is possible to look at the same phenomena from a different angle. In this case the explanation lies not in the formal relations that obtain between morphological constructions and phonological rules, but in the observation of patterns and quantitative relations in the relevant set of forms. To wit, while it is true that infectum-based affixation and perfectum-based affixation are very similar in terms of the phonological variation they display in affix allomorphy, they are in fact highly dissimilar in terms of the environments triggering the allomorphy (the environment being, as before, the stem-final segments).

In particular, infectum stems can end in any vowel (quality) except [o], and almost any consonant - the traditional conjugation classes are defined on this basis. All the classes are well populated, with many $i$ stems displaying systematic heteroclisy, but the only productive type appears to be the class of $a$-stems by Classical times. By contrast, perfectum stems end in consonants or [u] (these two types behave identically both in the infectum and in the perfectum), with only two exceptions: $i$ - 'go' (and its many prefixed forms) and desi- 'desist' are the only verbs whose perfectum stems end in the high front vowel. All other vowel-final perfectum stems can arise only via the optional affixdeletion process mentioned above (amav- $\sim$ ama- 'love', delev- $\sim$ dele'delete', nov- no- 'know', finiv- fini- 'finish' etc.), which thus creates an intra-lexemic allomorphy conditioned by the stem variants.

In quantitative terms, then, infectum and perfectum stems gravitate towards opposite ends of the sonority scale: infectum stems tend to end in more sonorous segments, whereas perfectum stems in less sonorous segments. Thus, unlike the infectum stems, the perfectum stems as environments overwhelmingly favour the vowel-initial variants of affixes, which may have exerted pressure for their retention. This pressure, however, only sufficed to favour vowel-initial affixes as far as the general hiatus rules of the language allowed it - and this is exactly what the abierat-type exemplifies.

\section{Conclusion}

In sum, then, I agree with those who do not assume a separate [ir] $>$ [er] (or [ur] $>$ [or]) change in the history of Latin. It is abundantly clear, at the same time, that the well-known patterns of vowel weakening in non-initial syllables created a large number of alternations that are best captured with a synchronic [ir] $\rightarrow$ [er] rule. Interestingly, however, the [e] that alternates with zero in the verbal morphology of Classical Latin behaves in two different ways in infectum-based vs. perfectum-based 
formations. In this paper I have briefly outlined two possible and tentative explanations for this: the difference can be captured in levelordered derivational models by assigning the two morphological subsystems to two different levels; but it can also be captured as a property that follows from quantitative patterns that differentiate infectum stems and perfectum stems as phonological environments, which thus exert different conditioning influence on allomorph choice.

\section{Comments invited}

PiHPh relies on post-publication review of the papers that it publishes. If you have any comments on this piece, please add them to its comments site. You are encouraged to consult this site after reading the paper, as there may be comments from other readers there, and replies from the author. This paper's site is here:

https://doi.org/10.2218/pihph.5.2020.4416

\section{Acknowledgements}

I presented an earlier version of this paper at the Fourth Symposium on Historical Phonology, Edinburgh, in December 2019. I am grateful to the participants for their comments; all remaining errors are mine.

\section{Author contact details}

András Cser

Institute of English and American Studies

Pázmány Péter Catholic University

Faculty of Humanities and Social Sciences

Szentkirályi u. 28.

Budapest 1088

Hungary

cser.andras@btk.ppke.hu

\section{References}

Baldi, Philip. 2002. The Foundations of Latin. Berlin-New York: Gruyter.

Buck, Carl Darling. 1933. Comparative Grammar of Greek and Latin. Chicago: University of Chicago Press.

Cser, András. 2015. The nature of phonological conditioning in Latin inflectional allomorphy. Acta Linguistica Hungarica 62. 1-35. 
Cser, András. 2020. The phonology of Classical Latin. Oxford-Malden: Wiley-Blackwell.

Hall, Tracy A. \& Silke Hamann. 2010. On the cross-linguistic avoidance of rhotic plus high front vocoid sequences. Lingua 120. 1821-1844.

Leumann, Manu. 1977. Lateinische Laut- und Formenlehre. München: Beck.

Meillet, Antoine. 1933 [1928]. Esquisse d'une histoire de la langue latine. Paris: Hachette.

Meiser, Gerhard. 1998. Historische Laut- und Formenlehre der lateinischen Sprache. Darmstadt: Wissenschaftliche Buchgesellschaft.

Parker, Holt N. 1988. Latin *siso > sero and related rules. Glotta 66. 221241.

Recasens, Daniel. 1990. The articulatory characteristics of palatal consonants. Journal of Phonetics 18. 267-280.

Recasens, Daniel. 1991. On the production characteristics of apicoalveolar taps and trills. Journal of Phonetics 19. 267-280.

Recasens, Daniel \& Maria Dolors Pallarès. 1999. A Study of / $/$ and /r/ in the Light of the 'DAC' Coarticulation Model. Journal of Phonetics 27. 143-169.

Rix, Helmut, Martin Kümmel, Thomas Zehnder, Reiner Lipp \& Brigitte Schirmer. 2001 [1998]. Lexikon der indogermanischen Verben: die Wurzeln und ihre Primärstammbildungen. Wiesbaden: Reichert.

Sen, Ranjan. 2015. Syllable and Segment in Latin. Oxford: Oxford University Press.

Sommer, Ferdinand. 1902. Handbuch der lateinischen Laut- und Formenlehre: eine Einführung in das sprachwissenschaftliche Studium des Lateins. Heidelberg: Winter. 4th edn. 1977, revised by Raimund Pfister.

Weiss, Michael. 2009. Outline of the Historical and Comparative Grammar of Latin. Ann Arbor: Beech Stave Press. 